\title{
IMAGENS DA INFÂNCIA: MÍDIAS E SUAS REPRESENTAÇÕES EM PRÁTICAS CORPORAIS INFANTIS ${ }^{1}$
}

\author{
Sheila da Silva Machado \\ Universidade de Brasília, Brasília, Distrito Federal, Brasil \\ Ingrid Dittrich Wiggers \\ Universidade de Brasília, Brasília, Distrito Federal, Brasil
}

\begin{abstract}
Resumo
O estudo teve como objetivo identificar e analisar práticas corporais infantis, de crianças entre 8 e 10 anos de idade, enfocando a presença da mídia em tais práticas. Foi realizada pesquisa de campo, de cunho qualitativo, envolvendo produção de dados em uma escola da rede pública de ensino do Distrito Federal, Brasil. As técnicas utilizadas compreenderam observação participante; coleta de desenhos; contato direto com crianças, por meio de conversas; e aplicação de "formulário sobre práticas culturais e de consumo de mídias". Os resultados apontam para a presença contumaz de discursos midiáticos no imaginário e em práticas corporais infantis. Por outro lado, as crianças perpetuam brincadeiras tradicionais.
\end{abstract}

Palavras-chave: Infância. Práticas Corporais. Mídias. Escola.

\section{Introdução}

Ao pensarmos na "infância" acreditamos que já sabemos tudo sobre ela. Nossos conceitos levam-nos a preverdo que as crianças gostam, o que são capazes de fazer, enfim, as etapas de seu desenvolvimento, como se a vida de cada criança obedecesse a uma ordem única e exata (LARROSA, 2003).Sob essa perspectiva, a sociedade e a escola tendem a ver a criança como um "ser que não é", ou seja, uma "pessoa que virá a ser". No entanto, ao nascer a criança já se movimenta e utiliza o corpo para explorar o mundo. Com o passar dos dias, meses e anos, ela aprende e forma características próprias que

1-O presente trabalho foi desenvolvido como conclusão do Curso de Especialização em Educação Física Escolar, da Faculdade de Educação Física, da Universidade de Brasília (UnB). O mesmo não contou com apoio financeiro de nenhuma natureza para sua realização.

Pensar a Prática, Goiânia, v. 15, n. 4, p. 821-1113, out./dez. 2012 
são obtidas por meio da sua interação com o contexto social em que vive. Portanto, a criança detém condições necessárias para perceber-se gradativamente enquanto parte da sociedade e ainda desenvolver certa autonomia.

Assim, ao ingressar na escola as crianças já trazem consigo conhecimentos relativos à matemática, língua, cores, formas, corpo, movimento, entre outros. Contudo, tais conhecimentos tendem a não ser valorizados pelas instituições e, sobretudo,percebe-se que há pouco lugar na escola para a criança e suas vivências particulares.A criança ao ser matriculada em uma instituição de ensino sofre mudanças bruscas em relação às suas experiências anteriores. Podemos afirmar que a escola matricula "alunos" e não "crianças". Geralmente, o que é imposto para a criança é o silêncio, o comportamento estático, a passividade, a obediência, o desprazer e a repetição. Na instituição educacional quase nada é permitido, conforme evidenciaram Richter e $\operatorname{Vaz}(2005$, p. 90):

[...] os momentos de atividade orientada situam-se num palco organizado por padrões escolarizantes: as crianças devem sentar direito nas cadeiras, alinhadas às mesas da sala e aguardar instruções para o trabalho previamente programado - segundo as professoras, "quem estiver sentado recebe primeiro". Quaisquer movimentos desviantes são interrompidos por ameaça: "Para", "Senta", "Espera senão...", "Senta, senão..." "Fica sentadinho, senão..."

Os autores analisaram a regulação corporal que é imposta às crianças no ambiente escolar. Segundo sua pesquisa de campo, elas não podem conversar, não podem rir e não podem sair das cadeiras, o que gera uma educação sem diálogo, sem ludicidade e sem movimento, respectivamente.Em contrapartida, seria impossível conceber uma educação integral ao deixar-se de lado o movimento corporal das crianças, provocando-se uma subvalorização da cultura corporal infantil (FREIRE, 1994). Então, que escola é essa onde não se pode ter prazer? Onde a obediência, a disciplina e a ordem são mais importantes do que a liberdade e a descoberta do saber como estímulos à solução de problemas? Diante disso, faz-se necessário repensarmos a educação de crianças. 
Cabe acrescentar ainda a relevância que a mídia ${ }^{2}$ vem exercendo na educação das crianças de hoje. Diversos autores concordam que a mídia é um componente dominante da cultura infantil contemporânea (FANTIN; GIRARDELLO, 2008; BELLONI, 2010). Nesse âmbito, a televisão é o meio de comunicação que possui maior representatividade, pois faz parte da quase totalidade dos lares brasileiros. Entre as alternativas de comunicação mais tradicionais, como o jornal, o rádio e o cinema, Penteado (2000) destaca que a televisão é a mais importante, podendo ser considerada como um padrão universal de nossa cultura.

De acordo com estudos sobre a relação entre as mídias e a infância, percebemos que a imagem da televisão é um ponto de partida para a formação do imaginário das crianças, tornando-se suporte para desenhos, brincadeiras e principalmente conversas entre elas, ao preencher o conteúdo das rodas infantis (GIRARDELLO, 2005; MUNARIM, 2007).A comunidade escolar também sofre de maneira contundente as influências da mídia, pois as crianças são telespectadoras assíduas (BELLONI, 2001). Segundo Girardello (2005), a televisão e as novas tecnologias de comunicação impõem mudanças em relação às concepções de infância.

Esse trabalho teve como objetivo principal identificar e analisar práticas corporais infantis, de crianças entre 8 e 10 anos de idade, enfocando a presença da mídia em tais práticas. Para tanto, foi realizada uma pesquisa de campo, de cunho qualitativo, envolvendo produção de dados em uma escola da rede pública de ensino do Distrito Federal, Brasil. As técnicas utilizadas compreenderam a observação participante de atividades escolares; contato direto com crianças, por meio de conversas; coleta de desenhos; e aplicaçãode "formulário sobre práticas culturais e de consumo de mídias".A pesquisacom as crianças buscou evidenciare interpretar olhares dos pequenos em relação ao fenômeno, procurando valorizá-los enquanto sujeitos de sua própria experiência.

2-No âmbito desse trabalho considera-se como mídia os meios de comunicação, como, internet, rádio, revistas, televisão, entre outros. Acrescente-se que mídia significa literalmente meios. De acordo com Belloni (2001, p. 45), mídia “[...] é a grafia brasileira da pronúncia inglesa da palavra latina 'media', plural de 'medium' que quer dizer meio". 


\section{Você se lembra de sua infância?}

"A infância tem as suas próprias maneiras de ver, pensar e sentir. Nada mais insensato que pretender substituí-las pelas nossas." (Jean-

Jacques Rousseau)

Várias recordações da infância se fazem presentes em nossa memória, como a família, as brincadeiras, os amigos, os medos, as histórias, as dúvidas e os aprendizados. Acontecimentos e mudanças marcam a nossa trajetória, como a perda da primeira dentição, a dor do crescimento e o ritual do primeiro dia de aula. Enfim, diversas "infâncias" se manifestam na nossa lembrança, incluindo momentos felizes e outros nem tanto.

Mas, apesar desses fatos, à criança ainda não se permite atuar como protagonista de sua história. Os pequenos são vistos como adultos em miniatura, ou seja, pessoas que ainda virão a ser um cidadão no futuro. Em geral, a criança é tratada como um ser que virá a adquirir uma visão de mundo, um ser que virá a ser capaz de agir com destreza, um ser que poderá vir a formar um autoconceito positivo.

Fundamentos dessa concepção são identificados em abordagens predominantemente oriundas da área biológica. Nessas as crianças são consideradas como seres naturais, que se desenvolvem de acordo com etapas preestabelecidas. Para tais teorias a habilidade motora é um dos conteúdos mais importantes para promover o desenvolvimento infantil, pois é por meio dela que os seres humanos se adaptam aos problemas do cotidiano. Segundo Gallahue e Ozmun (2005), o desenvolvimento motor caracteriza-se como um processo permanente de aprender a mover-se eficientemente, em reação ao que enfrentamos diariamente em um mundo em constante modificação.

Os autores acima mencionados recomendam expressamente a prática do esporte e de outras atividades motoras, pois essa ofereceria aos professores a ferramenta ideal para modelar o movimento das crianças e encorajar a socialização positiva entre elas. Tais propostas visam responder às necessidades das crianças em aprender a se movimentar de forma mais efetiva e eficiente para adaptar-se às demandas e exigências do cotidiano em termos de desafios motores. Além disso, nessa pedagogia, os conteúdos a serem ministrados devem estar em consonância com as necessidades determinadas pelo desenvolvimento esperado para cada faixa etária. 
Oliveira (2005) evidenciou que, sob essa perspectiva, a infância tem sido vista, tradicionalmente, no campo da Educação Física como um momento preparatório para a vida adulta, caracterizando-se como mera passagem. Ao ser assim compreendida, a criança é submetida a um processo de expropriação de sua condição de sujeito das relações sociais do seu tempo presente, ou seja, da sua própria infância. Segundo a autora, essa abordagem ainda confere pouca importância ao ambiente sociocultural que contextualiza a aquisição de habilidades motoras.

Desconsidera-se, sob esse ângulo, a criança como um ser que já se movimenta, tem a sua visão de mundo, apresenta necessidades próprias e é capaz de manifestar criatividade. A imagem da infância demonstrada por concepções alternativas a expõe, em contraste, como um “enigma”. Segundo Larrosa (2003, p. 184):

Pensar a infância como um outro é, justamente, pensar essa inquietação, esse questionamento e esse vazio. É insistir uma vez mais: as crianças, esses seres estranhos dos quais nada se sabe, esses seres selvagens que não compreendem a nossa língua.

Tais perspectivas tecem críticas aos modelos preconcebidos de explicação da infância. Demonstram a sua arrogância, procurando desmistificar a ciência, que tentaria reduzir o que existe de mistério nas crianças, para que se possa capturá-las e moldá-las dentro das instituições. Esses seres estariam para além do que sabemos, do que queremos ou até mesmo do que esperamos deles, como disse Larrosa (2003).Por conseguinte, para nos relacionarmos com as crianças, é necessário que aprendamos a conviver com o novo, ou seja, com o desconhecido.

No âmbito da Educação Física, por exemplo, poderíamos perguntar às crianças quais as práticas corporais que já experimentaram em seu cotidiano e, ainda, quais desejariam conhecer. Certamente, obteríamos uma lista numerosa de brincadeiras que enriqueceria o processo ensino-aprendizagem durante as aulas. Sob essa visão, a criança deveria ser abordada como um sujeito histórico e social, construído mediante suas relações com o meio e com o outro.

A partir da década de 1990, estudos sobre as crianças passaram a considerar o fenômeno social da infância, buscando superar métodos reducionistas (PINTO; SARMENTO, 1997). Conforme esses estudos, 
a criança merece ser tratada como sujeito ativo e de direitos, levandose em conta o seu contexto. Surgem, assim, diferentes representações de infância, descaracterizando-se seu caráter universal. Ver e ouvir a criança torna-se um novo objetivo das pesquisas e os dados passam a ser produzidos com as crianças, e não apenas sobre elas. Uma característica importante desses trabalhos é o registro das "falas" das crianças, como fizeram Kosminsky (1998), Wiggers (2005) e Corsaro (2011), entre outros.

\section{O sonho e o despertar de uma "Escola Colorida": uma visão do campo e dos procedimentos de investigação da pesquisa}

O delineamento da pesquisa se caracterizou por trabalho de campo realizado em uma escola da rede pública de ensino, localizada em Ceilândia, no Distrito Federal, Brasil. A cidade se situa em região periférica e a maior parte da comunidade pertence ou à classe social média ou à classe baixa. A instituição de ensino atende a crianças desde a educação infantil até os primeiros anos do ensino fundamental. Fundada em agosto de 1978, a escola fora, inicialmente, idealizada para ser uma "Escola Colorida",ou seja, voltada exclusivamente para o Ensino Infantil. Porém, devido às necessidades da comunidade local, após alguns anos tornou-se uma "Escola Classe". Entretanto, a estrutura física que caracteriza uma instituição de educação infantil foi mantida, com poucas adaptações. Acompanhamos uma turma do terceiro ano do Ensino Fundamental, formada por um total de vinte e seis crianças, de 8 a 10 anos de idade, entre elas, uma com necessidades especiais.

A pesquisa se desenvolveu por meio de abordagem qualitativa, procurando valorizar a expressão e oralidade das próprias crianças participantes. Ouvir as crianças faz parte do processo de buscar conhecê-las e entendê-las melhor. As técnicas utilizadas compreenderam a observação participante de atividades escolares; coleta de desenhos; contato direto com crianças, por meio de conversas; e aplicação de "formulário sobre práticas culturais e de consumo de mídias". A coleta de desenhos e as conversas com as crianças permitiram a identificação e interpretação de práticas corporais que as crianças vivenciam em seu cotidiano. Conforme Gobbi (2009) os desenhos infantis podem evidenciar a perspectiva das crianças cuja análise supera a observação. 
As conversas por sua vez,auxiliaram no entendimento do significado do conteúdo dos desenhos.

As evidências obtidas por meio dos registros da observação foram classificadas e organizadas em categorias, conforme os objetivos da pesquisa e acontecimentos que mereceram destaque (BOGDAN; BIKLEN, 1994).Os desenhos produzidos pelas crianças também foram interpretados em relação aos propósitos do trabalho, observando-se ainda os detalhes e explicações fornecidas pelas crianças durante as conversas. $\mathrm{O}$ formulário foi respondido pelas crianças participantes e preenchido pela própria pesquisadora. Os resultados do formulário complementam a apresentação dos resultados da pesquisa, pois fornecem dados de contexto e acesso das crianças a práticas culturais e de consumo de mídias.

\section{O imaginário midiático e suas representações em práticas corpo- rais infantis}

Soco, soco Lady Gaga

Soco, soco Beyoncé

Soco, soco Justin Bieber

Soco, soco eu e você.

(Letra adaptada por menina de 8 anos, para música da apresentadora Xuxa).

Conforme anteriormente assinalado, o objetivo principal do trabalho foi o de identificar e analisar práticas corporais infantis, de crianças entre 8 e 10 anos de idade, enfocando a presença da mídia em tais práticas, por meio de pesquisa de campo. A exposição dos resultados é desenvolvida em torno de categorias de análise que se fizeram significativas, tanto em relação ao referencial teórico quanto a partir do trabalho empírico. São elas: "espaço para brincadeiras"; "mídias como brinquedo"; "imaginário e corporalidade infantil". Adicionalmente, abordamos uma cena da prática pedagógica observada, que envolveu "dança e música na escola", considerando a sua importância para a expressão corporal infantil. 
a) Espaço para brincadeiras

Sobre os espaços aos quais as crianças têm acesso para brincar, a "praça" foi a resposta mais citada no "formulário de práticas culturais e consumo de mídias", tendo sido mencionada por $56 \%$ dos participantes. A praça foi inaugurada na cidade recentemente, em 2009. Ressalve-se que, embora comporte um parquinho e se localize em frente à escola, entre as quadras residenciais do bairro, muitas crianças destacaram os perigos da praça.

Minha mãe quase não me deixa ir, fica cheio de malandro lá, eles usam droga e mexem com a gente é perigoso. (aluna da turma, 8 anos)

Outro espaço importante para as brincadeiras das crianças é a própria "escola", que obteve $21 \%$ das respostas ao formulário. De acordo com Behmoiras (2011), a escola representa um "porto seguro" para a população jovem, pois nas ruas da cidade está sujeita às rivalidades entre gangues e à violência.

$\mathrm{Na}$ escola eu brinco muito, meus amigos estudam aqui, em casa fico sozinho e não posso sair (Menino, 8 anos).

Quando não estão na escola, muitas crianças são obrigadas a permanecer em "casa", que representou $22 \%$ das respostas relativas aos espaços onde acontecem as brincadeiras. As crianças, assim, se vêem impossibilitadas de brincar no parque ou em outros espaços do bairro, por falta de segurança. Entre os participantes, apenas um mencionou a Lan House do bairro como espaço que frequenta para brincar. Novas relações entre infância e cultura vêm se desenvolvendo no mundo contemporâneo, conforme observou Perrotti (1990, p. 92):

[...] o confinamento da infância ocasionou-lhe sérios problemas sócio-político-culturais. A cultura produzida pela infância livremente nos espaços públicos foi progressivamente sendo assimilada pelos espaços privados à medida que a urbanização e a vida burguesa avançavam. 
b) Mídias como brinquedo

Entre as brincadeiras feitas em casa se destacaram o "computador" e a "televisão", que atingiram $41 \%$ e $23 \%$ das respostas ao formulário de práticas culturais e consumo de mídias, respectivamente. Estas respostas também se evidenciaram nos desenhos produzidos pelas crianças, conforme ilustram as Figuras 1 e 2.

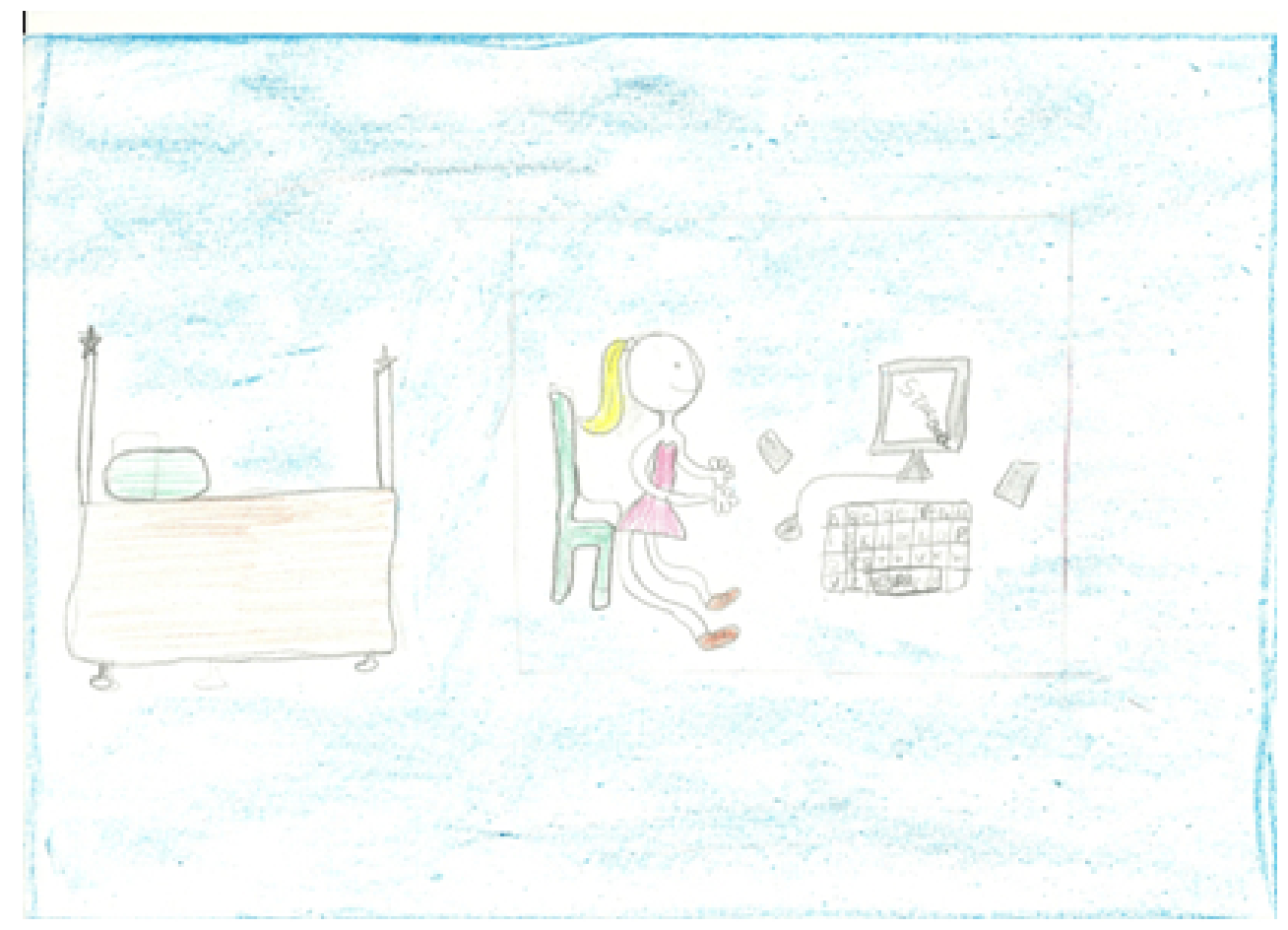

Figura 1: A bonequinha

A Figura 1 representa uma menina brincando de Stardoll no computador. Trata-se de uma comunidade virtual de bonecas de papel, onde as crianças escolhem modelos e acessórios para produzir sua própria bonequinha fashion. Ressalta-se que, embora a menina que produziu o desenho fosse morena, ela se desenhou como sendo loira. A menina evidenciou, assim, uma virtualização da imagem corporal, em acordo com a maioria das bonecas disponíveis para consumo, como, por exemplo, a Barbie, que foi lembrada por essa mesma criança. Considerando o conteúdo relacionado à moda e design, o Stardoll sugere, sobretudo, certo apelo ao consumismo.

A tendência ao consumismo de produtos veiculados por propagandas nos intervalos da programação infantil, também foi identificada durante as observações de campo. Tais produtos se evidenciaram em 
trajes, brinquedos, objetos pessoais e cartas de jogos, bem como nas próprias falas das crianças. Siqueira, Wiggers e Souza (2012), examinaram relações entre cultura corporal infantil e a presença das mídias em uma escola da região central de Brasília e verificaram, igualmente, a perspectiva do consumismo entre as crianças.

$\mathrm{Na}$ época do Natal, momento em que se desenvolveu o nosso trabalho de campo, as crianças enfatizam ainda mais o desejo por brinquedos e outros objetos, sobretudo os divulgados por meio de propagandas. Levando em conta a importância que as crianças dão aos presentes de Natal, solicitamos que desenhassem o que gostariam de ganhar. Os principais desenhos representaram a "casa da boneca Barbie", "computador", "videogame", "carros de brinquedos", "vestido de dama" e "patins".

Quero ganhar a casa da Barbie, Barbie moda e magia e um patinete, a boneca da Barbie fica aparecendo toda hora em qualquer lugar, no canal $12^{3}$ na propaganda (Menina, 8 anos).

Os brinquedos mais vendidos são aqueles que são objeto de campanhas publicitárias televisivas (BROUGÈRE, 2000). De acordo com o formulário de práticas culturais e consumo de mídias, todas as crianças disseram ter aparelho de televisão em casa. Assistir à televisão é uma das atividades preferidas pelas crianças, como mencionado acima.

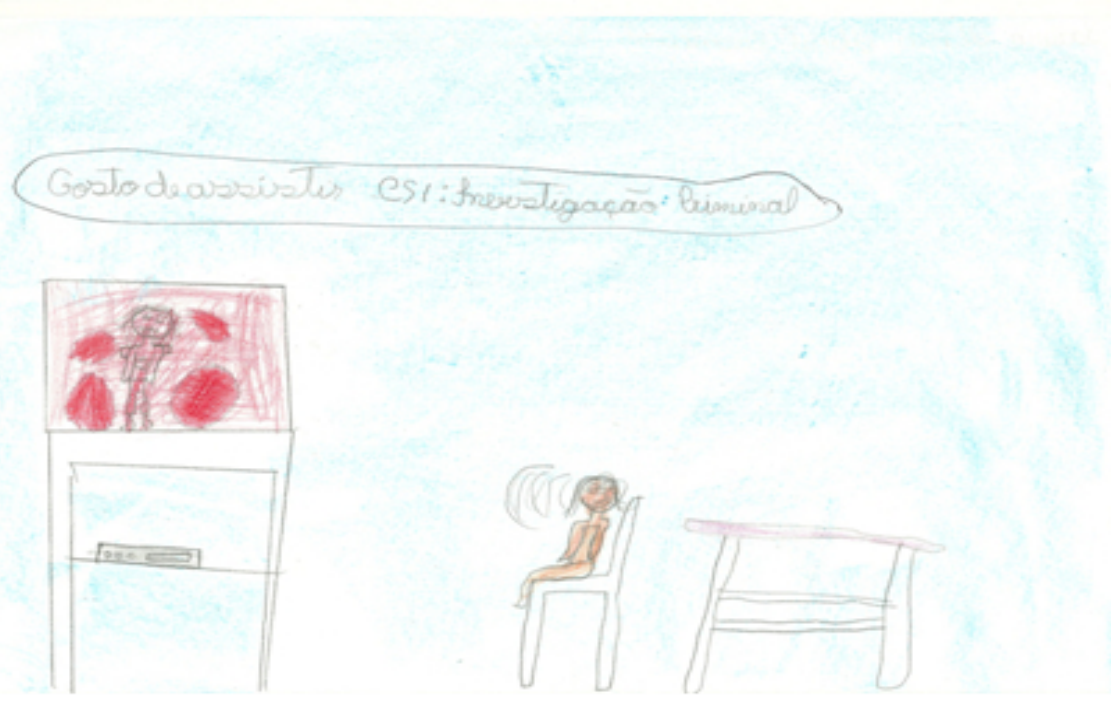

Figura 2: A telespectadora

3-Rede SBT de televisão aberta.

Pensar a Prática, Goiânia, v. 15, n. 4, p. 821-1113, out./dez. 2012 
Sobre esse aspecto, destacaram-se tanto nos desenhos coletados quanto em falas, preferências por programas que tematizam a violência. Entre esses, a série "CSI: Investigação Criminal" 4 foi a mais comentada durante as conversas registradas.

Você assistiu CSI ontem? Foi muito legal, muita gente morre e o sangue aparece na tela (Conversa entre crianças).

Observamos, portanto, que as crianças assistem não somente aos desenhos animados, mas programas destinados ao público de maior faixa etária também estão no rol de suas preferências. Notamos ainda que o conteúdo da série fazia parte das brincadeiras na hora do recreio, pois as crianças simulavam lutas, por meio de golpes imaginários, que eram executados com movimentos típicos das artes marciais. Assim como na série, essas lutas dramatizavam uma cena de crime, que passava a ser objeto de diligência das crianças que representavam o papel de investigadores. A brincadeira terminava quando esses "descobriam" os vestígios e pistas deixadas pelos criminosos, "desvendando" a cena.

De acordo com Girardello (2005), as mídias oferecem conteúdos para as brincadeiras, preenchendo o imaginário das crianças com suas mensagens e valores. Para Munarim (2007) há relação direta entre a cultura corporal infantil e a interlocução das crianças com a mídia televisionada. Porém, segundo as autoras, não é somente o consumo das programações que influenciam as crianças a praticar brincadeiras que tematizam a violência. Belloni (2001, p.38), acrescenta que "a recorrência das imagens violentas na TV faz com que violência física seja percebida como 'natural', como meio eficaz de resolver conflitos, como modo natural de brincar e interagir com os pares".

c) Imaginário e corporalidade infantil

Outras atividades ocupam lugar de destaque na cultura infantil. Entre as meninas a brincadeira de "pular corda" foi assinalada por $80 \%$ como sendo a preferida (Figura 3). Além dessa, outros jogos tradicionais foram representados por elas, como, por exemplo, a "quei-

4-Trata-se de uma série produzida nos EUA e exibida no Brasil pela rede Record de televisão aberta. É recomendada para maiores de 14 anos.

Pensar a Prática, Goiânia, v. 15, n. 4, p. 821-1113, out./dez. 2012 
mada" e o "pique-cola". Da mesma forma, Cunha (2007) percebeu a presença de jogos antigos no universo lúdico infantil, durante o seu trabalho de campo com crianças. A permanência de brincadeiras tradicionais nesse universo sugere que, por um lado a mídia influencia as práticas corporais infantis, por outro não determina por completo o conteúdo de tais práticas.

Eu desenhei eu pulando corda. Desde pequena minha irmã me ensinou. É o que eu mais gosto de fazer na escola (Menina, 8 anos, autora da Figura 3).

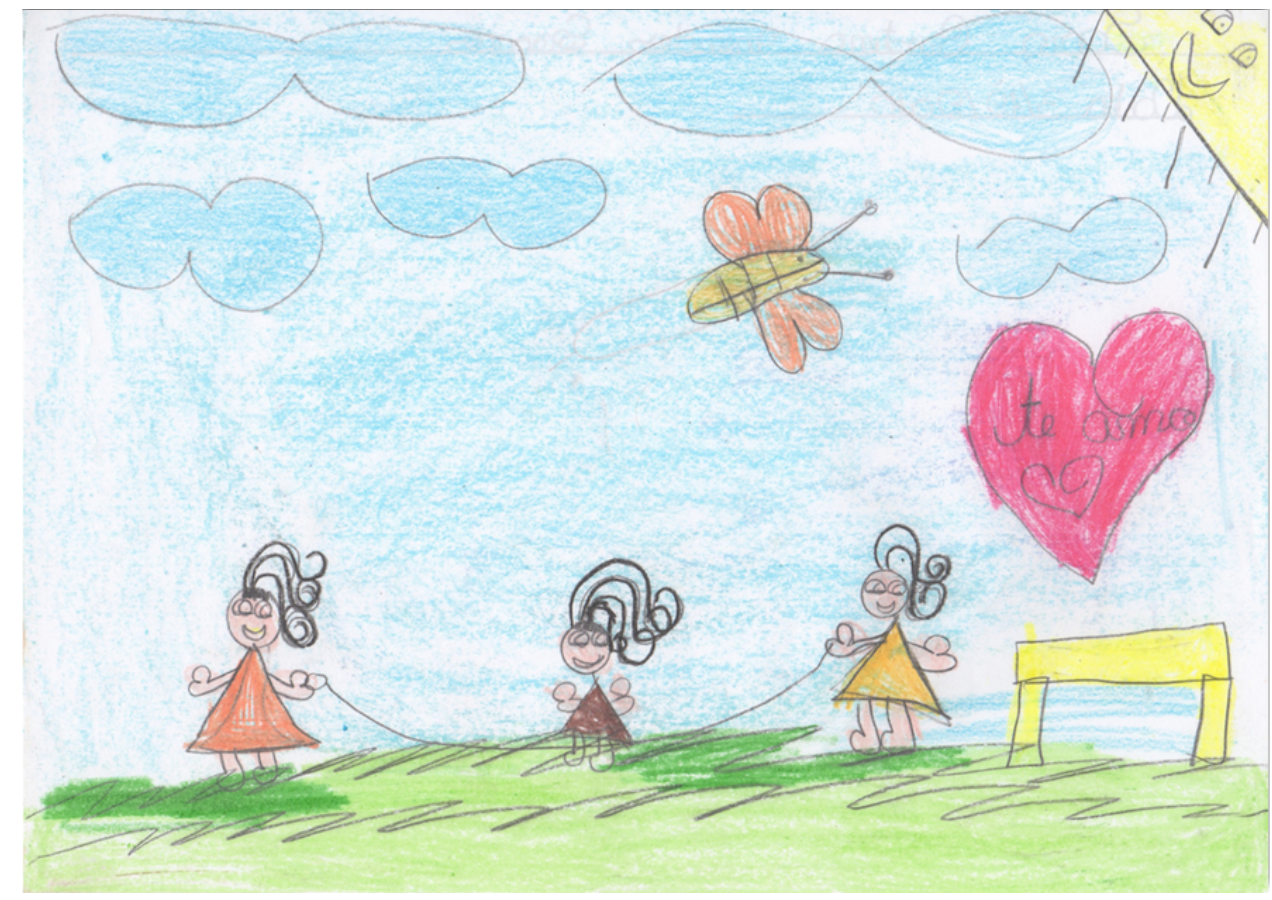

Figura 3: Pulando corda na escola

Os meninos, por sua vez, preferem "pique-pega" e esportes, como o "basquete" e o "futebol", sendo que $99 \%$ deles consideram o futebol como a brincadeira preferida (Figura 4). Mais do que isso, o sonho de ser jogador de futebol está presente no seu imaginário. Esse sonho é reconhecidamente enfatizado pelas mídias, que exploram a ascensão econômica e social de atletas bem sucedidos de grandes times nacionais e estrangeiros, como argumento publicitário (BETTI, 1998).

Meu pai me ensinou desde pequeno. Gosto de futebol, estou jogando com o D... Quero ser jogador igual o Robinho e torço pro Flamengo (Menino, 8 anos, autor da Figura 4). 


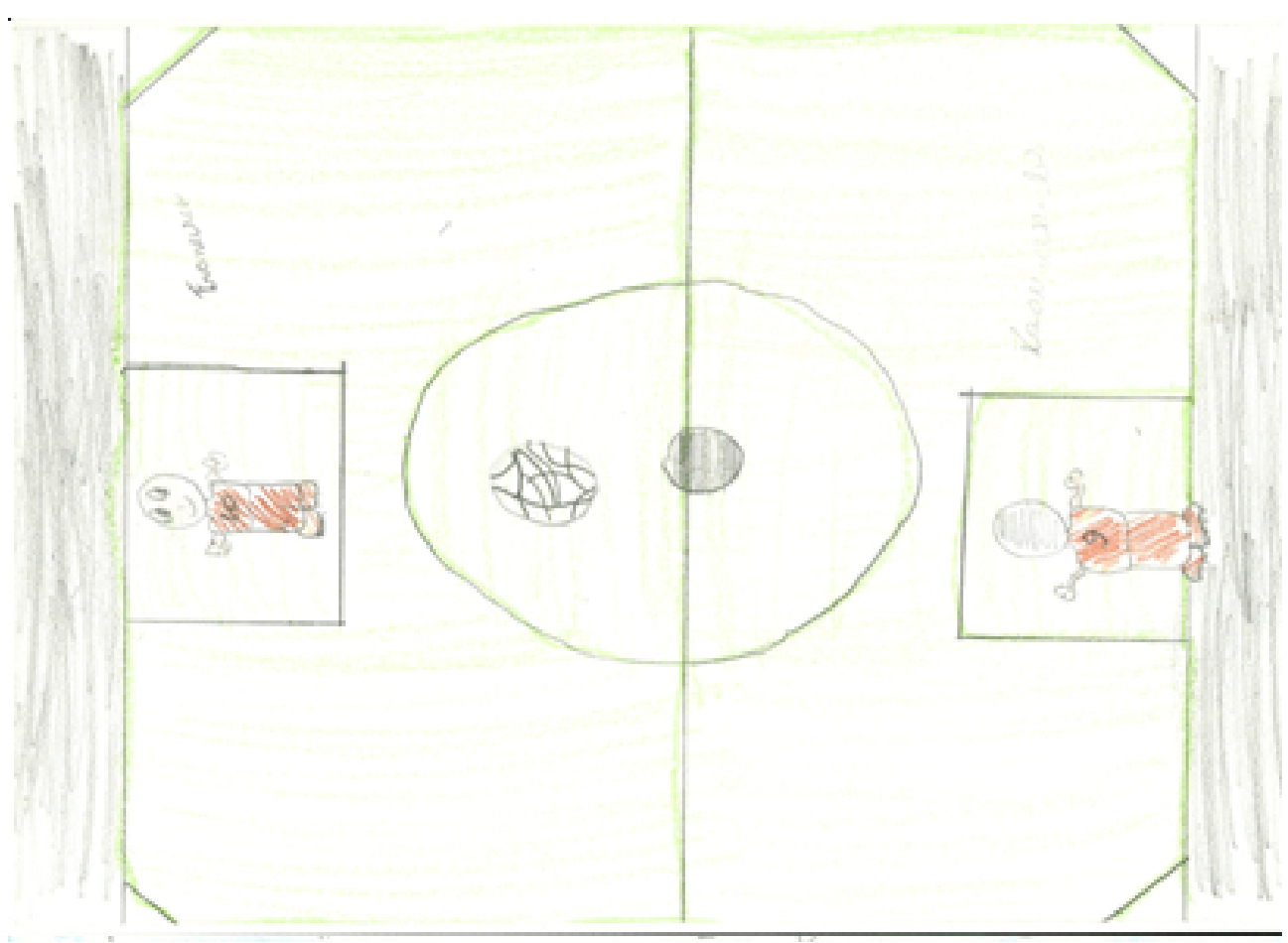

Figura 4: O jogador de futebol

Além das brincadeiras preferidas, as crianças evidenciaram, por meio dos desenhos, imagens de corpo, bem como suas projeções futuras, ou seja, como desejam se tornar ao crescerem (Figuras 5 e 6 ).

Sou muito fã do Justin ${ }^{5}$ e da Lady Gaga ${ }^{6}$. Eles são os melhores de todos, gosto de suas músicas, mas não sei cantar. Gosto mesmo é de desfilar porque sou igual a Gisele Bündchen ${ }^{7}$ (Menina, 8 anos, autora da Figura 5).

Sou um jogador de basquete, gosto de jogar basquete, vou ganhar muito dinheiro e namorar uma menina linda... (Menino, 7 anos, autor da Figura 6).

5-Justin Bieber é cantor de música pop e ator canadense. Suas apresentações foram vistas, inicialmente, no You Tube.

6-Lady Gaga é cantora, compositora e produtora musical nos Estados Unidos. Foi considerada uma das vinte e cinco pessoas mais influentes e uma das cinco mais bem remuneradas do mundo.

7-Top model brasileira mais bem sucedida no cenário internacional desse período. 


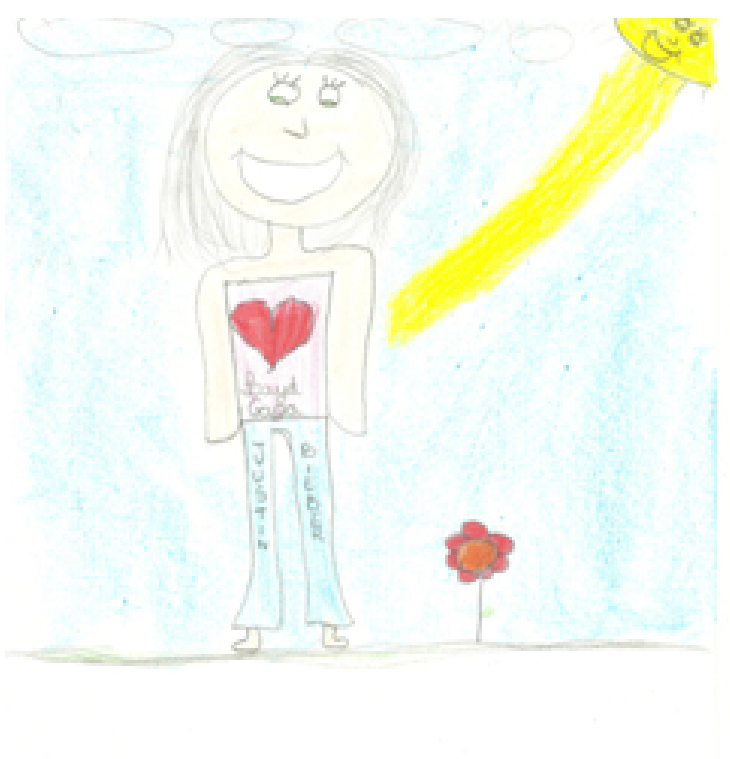

Figura 5: A fã

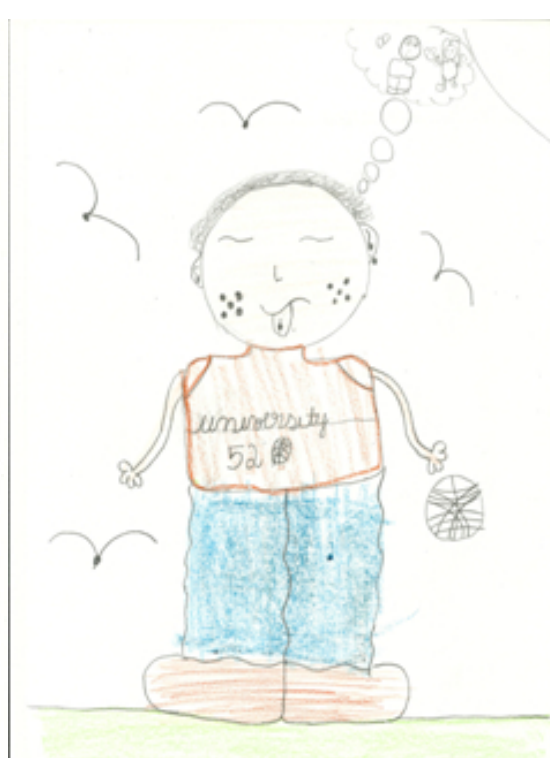

Figura 6: O jogador de basquete

Girardello (1998) disse que a imaginação é uma dimensão por meio da qual as crianças reagem às novidades do mundo, pressentindo ou esboçando possibilidades futuras. Sugeriu que é, por meio do imaginário, presente em brincadeiras, desenhos e diálogos que as crianças buscam elementos para enfrentar o desconhecido, moldando suas representações de acordo com suas expectativas. Percebemos que o mundo demonstrado pela mídia é refletido na corporeidade das crianças, tal como Wiggers (2005), que evidenciou a estreita relação entre mídias e representações corporais no universo infantil.

c) Dança e música na escola

Outro desenho coletado denotou o interesse das crianças pela dança e pela música, na escola. Às sextas-feiras, a professora da turma reservava um espaço da aula para as crianças ouvirem e dançarem as suas músicas preferidas. A Figura 7 é uma ilustração dessa atividade.

Para mim, este é o melhor dia (Menina, 8 anos, autora da Figura 7). 


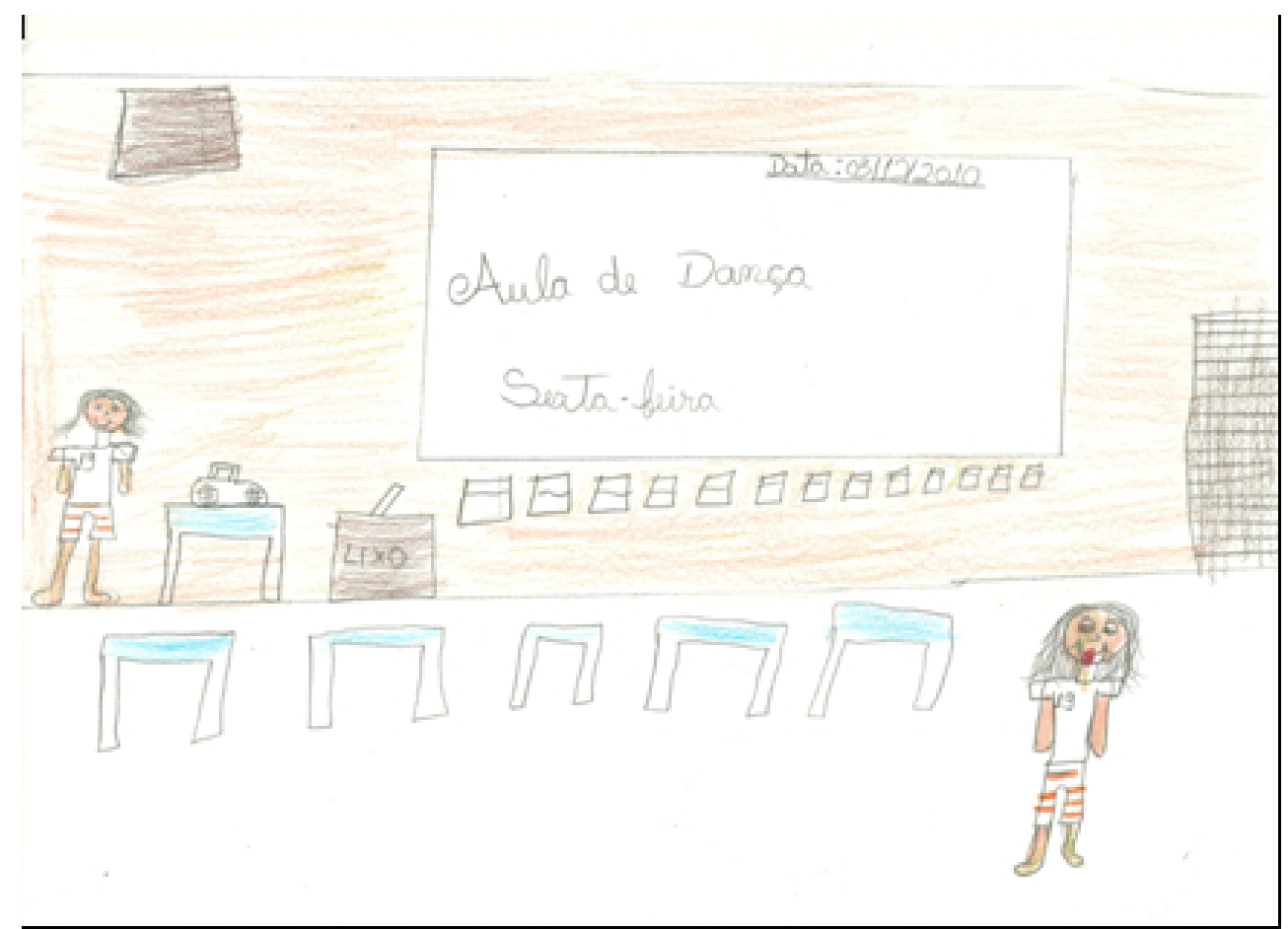

Figura 7: Aula de dança

Por um dia, a escola oportuniza para essas crianças exercício de autonomia, pois elas próprias decidem quais músicas serão ouvidas e dançadas. Notamos a influência das mídias na escolha das músicas e nos gestos. Mas, por outro lado, nessa aula os pequenos se tornam protagonistas e o corpo se movimenta e brinca com relativa liberdade, em oposição ao "processo civilizador" que as crianças são submetidas na instituição educacional, conforme evidenciaram Richter e Vaz (2005). Essa transgressão faz desse o "melhor dia na escola", o que sugere a importância de buscarmos novas possibilidades de ação pedagógica na educação de crianças.

\section{Considerações finais}

Como vimos, a mídia está presente de forma contumaz no imaginário e nas práticas corporais infantis. As crianças passam muito tempo dentro de seus lares brincando no computador ou assistindo à televisão, entre outros motivos, por causado elevado índice de violência na cidade. Brincadeiras feitas com as mídias, denotaram uma tendência ao consumismo, que foi evidenciada nos trajes, brinquedos e objetos pessoais, que representam novidades e produtos amplamente divulgados pela publicidade. 
As crianças ainda demonstraram que o conteúdo de mensagens midiáticas é utilizado para inventar e desenvolver novas brincadeiras. Entre essas, mensagens de teor violento veiculadas pela televisão foram por elas exploradas. Embora a televisão exerça influência significativa nas práticas corporais infantis, esse não foi o único traço determinante dessas práticas, pois as crianças demonstraram grande interesse por brincadeiras tradicionais, como "pular corda", "piquecola", "futebol" e "pique-cola", entre outras.

Por fim, cabe ressaltar que à escola, por ser instância privilegiada de socialização das novas gerações, se impõe o desafio de oferecer mediações pedagógicas relacionadas às mídias. Segundo Belloni (2010), caberia ao professor, por meio da sua prática pedagógica, interferir criticamente nos efeitos pedagógicos das mídias, de modo que suas mensagens sejam questionadas e refletidas pelas crianças. Faz-se mister que a escola ofereça instrumentos para que as crianças façam escolhas e apropriações dos discursos midiáticos de forma crítica e autônoma, completam Fantin e Girardello (2008).

Images of childhood: the media culture representations and practices in children's body

\begin{abstract}
The study aimed to identify and analyze bodily practices for children, children between 8 and 10 years of age, focusing on the media presence in such practices. We performed field research, a qualitative, involving production of data in a public school education in the Federal District, Brazil. The techniques used comprised participant observation, collection of drawings, direct contact with children, through conversations, and application of "form over cultural practices and consumption of media." The results indicate the presence of media discourse in the stubborn imagination and bodily practices in children. Moreover Children perpetuate traditional games.
\end{abstract}

Keywords: Childhood. Body practices.Media. School.

Imágenes de la infancia: la cultura de los medios de comunicación y sus representaciones en las prácticas del cuerpo de los niños

\title{
Resumen
}

El estudio tuvo como objetivo identificar y analizar las prácticas corporales de los niños, los niños de entre 8 y 10 años de edad, centrándose en la presencia de los medios en estas prácticas. Se realizó investigación de campo, uno cualitativo, que implica la producción de datos en una educación pública en el Distrito Federal, Brasil. Las técnicas que utilizó la observación participante comprende, colección de dibujos, el contacto directo con los niños, a través de conversaciones, y la apli- 
cación de "la forma sobre prácticas y consumos culturales de los medios de comunicación." Los resultados indican la presencia de un discurso mediático en la imaginación terca y prácticas corporales en los niños. Por otra parte los niños perpetúan los juegos tradicionales.

Palabras clave: Infancia. Prácticas Corporales.Los Medios de Comunicación. La Escuela.

\section{Referências}

BEHMOIRAS, D. C. Educação física escolar e sua interface com o esporte e a mídia. Dissertação (Mestrado em Educação Física) - Faculdade de Educação Física. Brasília, Universidade de Brasília, 2011.

BELLONI, M.L. O que é mídia-educação. Campinas: Autores Associados, 2001.

. Crianças e mídias no Brasil: cenários de mudança. Campinas: Papirus, 2010.

BETTI, M. A janela de vidro: esporte, televisão e Educação Física. Campinas: Papirus, 1998.

BROUGÈRE, G. Brinquedo e cultura. 3. ed. São Paulo: Cortez, 2000 .

BOGDAN, R.; BIKLEN, S. Investigação qualitativa em educação: uma introdução à teoria e aos métodos. Porto: Porto, 1994.

CORSARO, W. A. Sociologia da infância. 2. ed. Porto Alegre: Artmed, 2011.

CUNHA, C. Mídia e criança: a permanência dos jogos tradicionais. In: XV CONGRESSO BRASILEIRO DE CIÊNCIAS DO ESPORTE e II CONGRESSO INTERNACIONAL DE CIÊNCIAS DO ESPORTE, 15.,2007, Recife. Anais... Recife: CBCE, 2007, v. 1, p. 1-8.

FANTIN, M.; GIRARDELLO, G. (Orgs.). Liga, roda, clica: estudos em mídia, cultura e infância. Campinas: Papirus, 2008.

FREIRE, J. B. Educação de corpo inteiro: teoria e prática.São Paulo: Scipione, 1994. 
GALlAHUE, D. L.; OZMUN, J. C. Compreendendo o desenvolvimento motor: bebês, crianças, adolescentes e adultos.3. ed. São Paulo: Phorte, 2005.

GIRARDELLO, G.Televisão e imaginação infantil: histórias da Costa da Lagoa. 1998. 349 f. Tese (Doutorado em Comunicação) Escola de Comunicação e Artes, Universidade de São Paulo, São Paulo, 1998.

. Produção cultural infantil diante da tela: da TV à internet. In: $28^{\mathrm{a}}$. REUNIÃO ANUAL DA ANPED, 28.,2005, Caxambu. Anais... Rio de Janeiro:ANPED, 2005, v. 1, p. 1-16.

GOBBI, M. Desenho infantil e oralidade: instrumentos para pesquisas com crianças pequenas. In: FARIA, A. L. G.; DEMARTINI, Z. B. F.; PRADO, P. D. (Orgs.). Por uma cultura da infância: metodologia de pesquisas com crianças. Campinas: Autores Associados, 2009. p. 6992.

KOSMINSKY, E. V. "Aqui é uma árvore. Aqui o sol, a lua. Aqui um montão de guerra": o uso do desenho infantil na sociologia. In: Cadernos CERU. São Paulo: 1998, v. 2, n. 9, p. 83-100.

LARROSA, J. Pedagogia profana: danças, piruetas e mascaradas.Belo Horizonte: Autêntica, 2003.

MUNARIM, I. Brincando na escola: o imaginário midiático na cultura de movimento das crianças.2007. 189 f.Dissertação (Mestrado em Educação)- Centro de Ciências da Educação. Universidade Federal de Santa Catarina, Florianópolis, 2007.

OLIVEIRA, N. R. C. Concepção de infância na educação física brasileira: primeiras aproximações. In: Revista Brasileira de Ciências do Esporte. Campinas, v.26, n.3, p.95-109, maio/2005.

PENTEADO, H. D. Televisão e escola: conflito ou cooperação? São Paulo: Cortez, 2000.

PERROTTI, E. Confinamento cultural, infância e leitura. São Paulo: Summus, 1990. 
PINTO, M. e SARMENTO, M. J.(Coords). As crianças: contextos e identidades. Braga: Universidade do Minho, 1997.

RICHTER, A. C.; VAZ, A. F. Corpos, saberes e infância:um inventário para estudos sobre a educação do corpo em ambientes educacionais de 0 a 6 anos. In: Revista Brasileira de Ciências do Esporte, Campinas, v. 26, n. 3, maio/jun. 2005, p. 79-93.

SIQUEIRA, I. B.; WIGGERS, I. D.; SOUZA, V. P. O brincar na escola: a relação entre o lúdico e a mídia no universo infantil. In: Revista Brasileira de Ciências do Esporte. Campinas, v. 34, n. 2, abr./jun. 2012, p. 64-79.

WIGGERS, I. D. Cultura corporal infantil: mediações da escola, da mídia e da arte. In: Revista Brasileira de Ciências do Esporte. Campinas, v.26, n. 3, maio/jun. 2005, p.59-78.

Agradecimentos: Ao Prof. Juarez Oliveira Sampaio (UnB)que integrou a comissão examinadora do trabalho, pelas análises e considerações durante a apresentação no encerramento do Curso de Especialização em Educação Física Escolar (UnB), em 2010 .

Recebido em: 30/09/2011

Revisado em: 25/01/2012

Aprovado em: 27/05/2012

Endereço para correspondência

Ingrid Dittrich Wiggers

ingridwiggers@gmail.com

Universidade de Brasília, Faculdade de Educação Física.

Gleba B - Campus Darcy Ribeiro

Asa Norte

70910-900 - Brasilia, DF - Brasil 